\title{
Secondary prevention clinics: improving quality of life and outcome
}

\section{N C Campbell}

Heart 2004;90(Suppl IV):iv29-iv32. doi: 10.1136/hrt.2004.037606

General practitioners have been encouraged to target patients with coronary heart disease for secondary prevention, but putting this into practice has proven challenging. However, there is now evidence of the benefits from nurse led clinics in primary care. Randomised trials have shown that such clinics can lead to improvement in both medical and lifestyle components of secondary prevention. This has in turn been associated with improved quality of life and a reduction in mortality. Benefits are conditional on several factors: in particular, risk factors are only reduced if clinic attendance is accompanied by appropriate prescribing, and improvements in risk factors are only sustained if the clinics are continued.

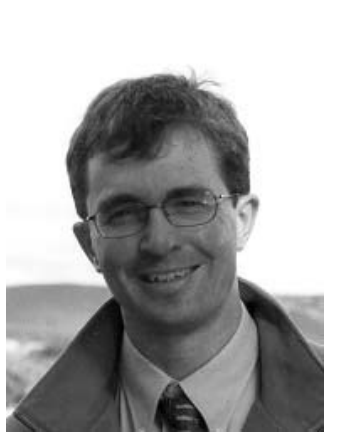

$\mathrm{T}$ he past 15 years have seen increasing evidence of the benefits of secondary prevention in patients with established coronary heart disease (CHD). Intervention can reduce coronary events and mortality in these patients, and guidelines are available on the appropriate treatments and lifestyle interventions. ${ }^{12}$

General practitioners have been encouraged to target patients with CHD for secondary prevention. Putting this into practice in primary care has proven challenging, however, as the issue is both complex and multifactorial. One of the challenges is the high prevalence of coronary disease-about $5 \%$-in a general practice population. Although the incidence and the death rate from CHD are decreasing, its prevalence is increasing. Another challenge is that the majority of people with CHD are aged over 70 years.

The National Service Framework (NSF) for CHD advocates structured secondary prevention clinics, ${ }^{1}$ usually run by nurses, to assess risk factors, promote lifestyle measures, such as smoking cessation, increased exercise and healthy diet, and ensure people are prescribed optimum drug treatments. In addition to secondary prevention, these clinics offer the opportunity for symptom control.

There is now evidence from four randomised trials of secondary prevention clinics. All four trials were nurse led (table 1). Three of them were carried out in primary care in the $\mathrm{UK}^{3-7}$ and one was carried out in hospital practice in the USA. ${ }^{8}$ Two of the trials had reasonably long term follow up (4.7 and 5 years).

All of the trials assessed effects on lifestyle and health behaviour. As shown in fig 1, the three trials that measured exercise all found a notable improvement compared with the control group.
There was a large relative increase, which can be explained by the fact that the baseline level of exercise was so low. In the north east Scotland trial, "moderate exercise" improved from $31 \%$ to $42 \%$ and in Belfast, daily physical exercise from $24 \%$ to $44 \%$.

There were significant, but smaller, improvements in diet in the intervention groups. However, there was no impact on smoking in any of the trials. This is a common finding in trials of smoking cessation in a general unselected population; those trials that have had positive results have tended to involve motivated patients.

With regard to drug treatment, two of the trials assessed aspirin prescribing and found that it improved significantly; all four trials assessed lipid management, but only two of these showed significant improvement (fig 2). Three of the trials assessed effects on blood pressure, but in only one of these was there any significant improvement. However, it is important to note that the Belfast study did not aim to increase drug prescribing. The trial was carried out in the early 1990s and concentrated on health promotion and lifestyle issues.

Excluding the Belfast study for that reason, only in those trials where prescribing increased did lipid and blood pressure levels improve. The finding that prescribing did not always increase in the other studies illustrates a general problem with secondary prevention. Modifying risk is complex: patients first have to be identified, their risk has to be assessed, and then action needs to be taken to facilitate behaviour change and to prescribe preventive drugs. Secondary prevention clinics can improve risk factors but only if the initial assessment is followed up and leads to improved prescribing.

Three of the randomised trials investigated quality of life: in the Belfast trial quality of life was measured by Nottingham health profile, in the NE Scotland trial the short form (SF)-36 health survey questionnaire was used, and the Warwickshire trial used Dartmouth COOP charts and the EuroQol questionnaire. Two of the trials ${ }^{4}{ }^{5}$ reported significant benefits while one showed no changes. ${ }^{7}$ Figure 3 shows percentage changes in various domains of health related quality of life from the NE Scotland trial. The Belfast trial results are similar. There was no impact on anxiety and depression, as measured by changes in mental scores. The greatest improvement was in physical functioning; interestingly, the physical functioning scores were where the trial population scored most poorly at baseline. People with coronary artery disease may have a high risk of anxiety and depression, 
Table 1 Randomised trials of nurse led secondary prevention clinics

\begin{tabular}{|c|c|c|c|c|}
\hline Author & Participants & Setting & Intervention(s) & Follow up \\
\hline $\begin{array}{l}\text { Cupples and } \\
\text { McKnight }^{34}\end{array}$ & 688 patients with angina & 18 Belfast practices & $\begin{array}{l}\text { Health promotion every } 4 \text { months for } \\
2 \text { years }\end{array}$ & 2 and 5 years \\
\hline Murchie et $a^{56}$ & 1343 patients with $\mathrm{CHD}$ & 19 NE Scotland practices & Clinics every $2-6$ months for 1 year & 1 and 4.7 years \\
\hline Moher et al & 1906 patients with CHD & 21 Warwickshire practices & $\begin{array}{l}\text { (1) Clinics (as above) } \\
\text { (2) General practitioner recall } \\
\text { (3) Audit and feedback }\end{array}$ & 18 months \\
\hline Allen et $a^{\beta}$ & 228 patients with $\mathrm{CHD}$ & 1 Maryland hospital & Lipid management clinics for 1 year & 1 year \\
\hline
\end{tabular}

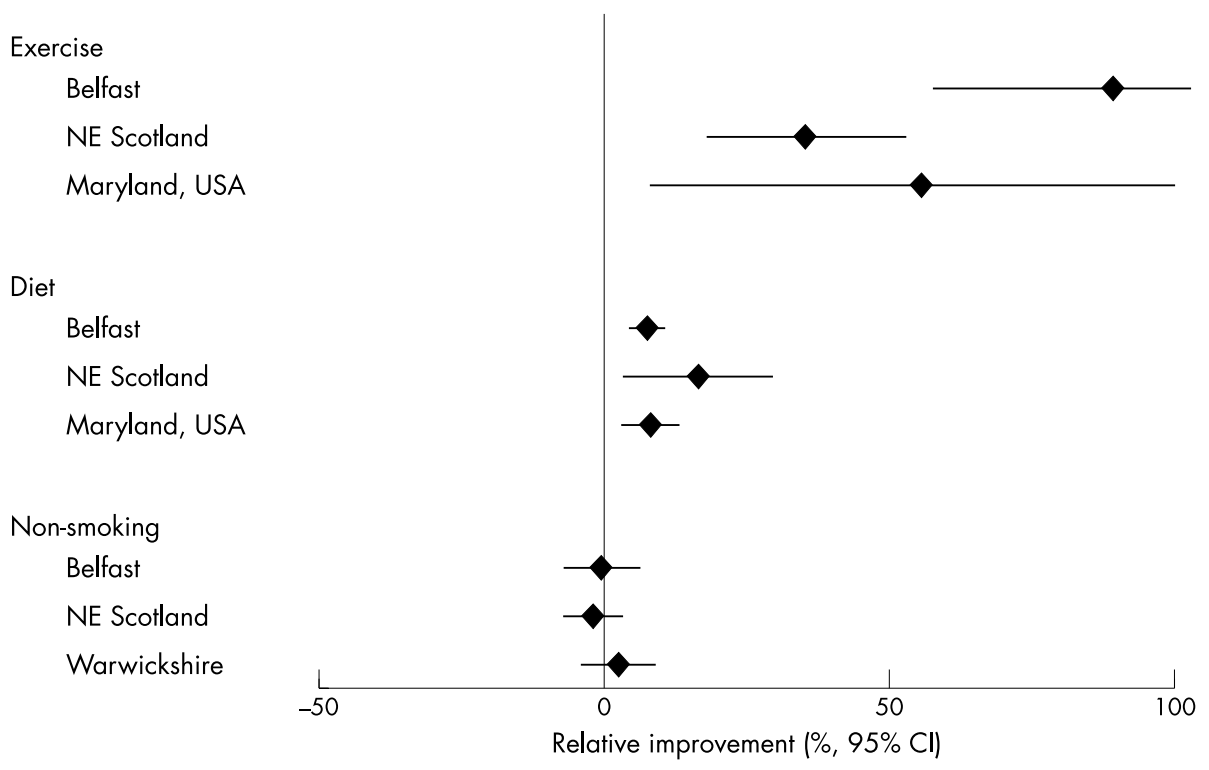

Figure 1 Effect of nurse led clinics on health behaviour. The figure shows the percentage improvement in the intervention group compared to the control group (comparing mean scores for diet in Belfast and Maryland and proportions reaching targets elsewhere).

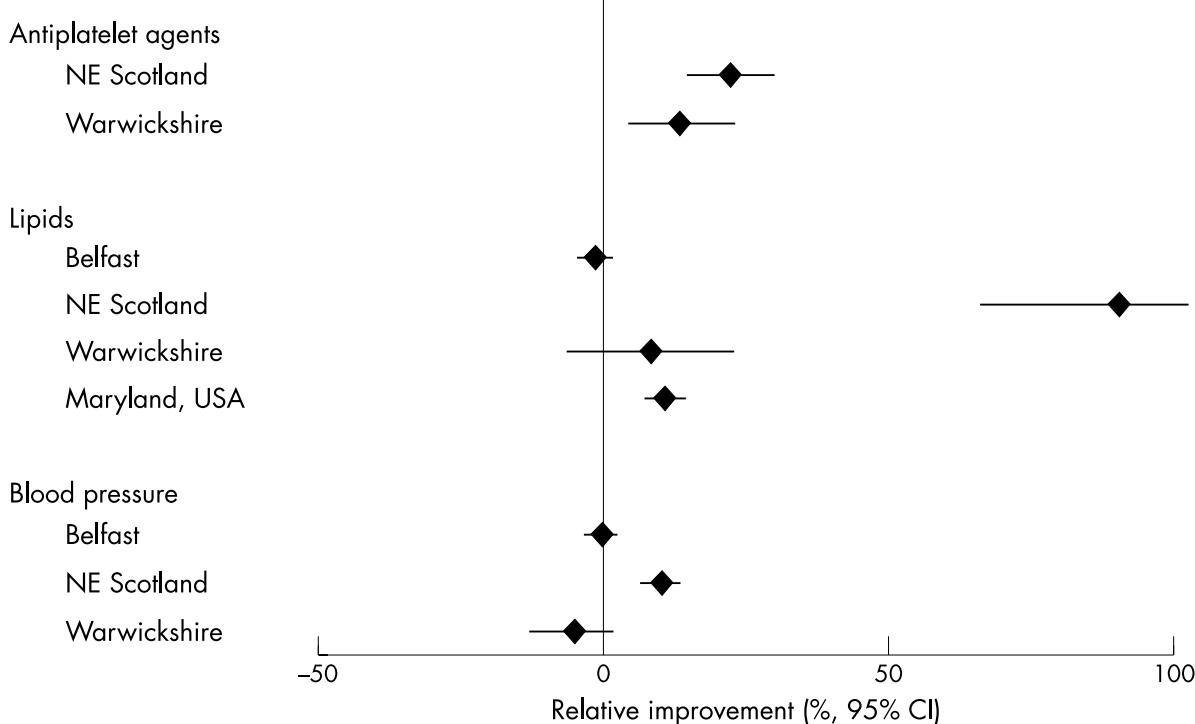

Figure 2 Effect of nurse led clinics on drug treatment and risk factors. The figure shows the percentage improvement in the intervention group compared to the control group (mean values for total cholesterol and systolic blood pressure are compared for the Belfast and Maryland studies and proportions on treatment or reaching argets elsewhere).

but for those in general practice the main impact on quality of life relates to their physical functioning.

\section{MORTALITY}

The trials have therefore shown some improvement in quality of life and incremental (although not optimal) improvement in the components of secondary prevention compared with control groups. A key question is whether the intervention has any effect on total mortality. Two of the trials with longer term follow up -5 years ${ }^{4}$ and 4.7 years ${ }^{6}$ - both showed lower mortality in the intervention group than the control group. The Belfast data did not quite reach significance, but the result was significant in the NE Scotland study $(p=0.038)$. If the results from the two trials were pooled, the estimate of benefit is likely to remain the same, but the confidence intervals would narrow.

There does, therefore, appear to be good evidence that secondary prevention clinics can reduce mortality. The 


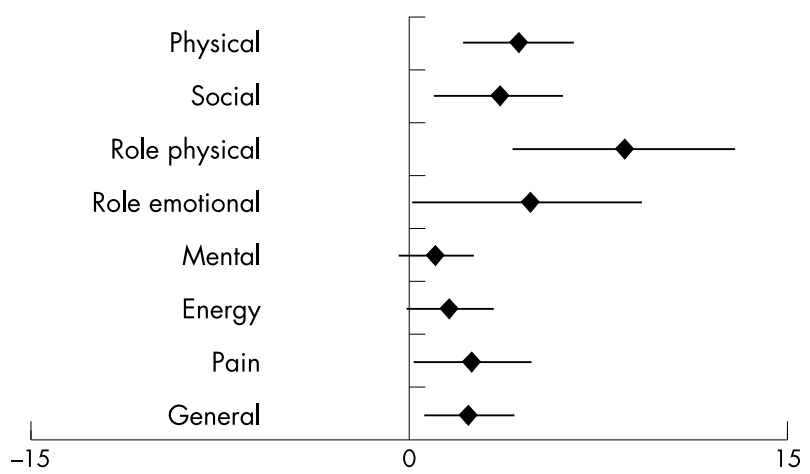

Figure 3 Effect of nurse led clinic on quality of life-percentage change in SF-36 scores, clinic versus control. Higher score represents improvement. ${ }^{5}$

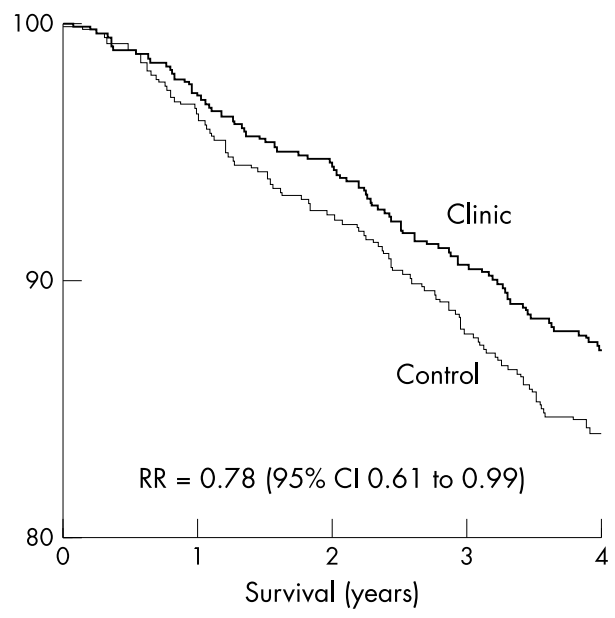

Figure 4 Effect of nurse led clinic on total deaths. Adapted from Murchie et $a^{\beta}$ with permission. $\mathrm{Cl}$, confidence interval; RR, relative risk.

benefit starts within the first year, and then gradually broadens, reducing deaths by $22 \%$ by 4.7 years (fig 4 ). The NE Scotland trial was not designed to be large enough to show mortality differences: that significant differences were observed is due not only to the effectiveness of the intervention but also the high death rate in the control group: after 4.7 years, 128 of the 670 patients had died, compared with 100 out of 673 in the intervention group.

There was a similar reduction in coronary events (coronary deaths and non-fatal myocardial infarction); the result did not reach significance $(\mathrm{p}=0.052)$ but followed almost the exact pattern as total mortality. This is because the vast majority of deaths were coronary deaths and, in this group, most coronary events were deaths.

The two trials with longer follow up had a different design: in the Belfast study, the intervention was run for two years and then stopped; patients were then followed up at five years at which point most of the benefits to secondary prevention identified at the end of two years had worn off. In the Scottish trial, the intervention was run for one year and then stopped, but the results were fed back to the practices which then decided their own policies for running the clinics, and these were extended to the control group. At follow up after 4.7 years, the benefits to secondary prevention (compared with baseline) had persisted in the intervention group, but the control group, most of whom were now attending clinics, had caught up. These two trials thus demonstrate, indirectly, that the benefits persist if the intervention persists, but wear off if the intervention ceases. Sustained benefit is conditional on sustained clinics.

\section{CONCLUSION}

Nurse led secondary prevention clinics can improve secondary prevention in primary care-and, as judged by the US trial, in hospital too. Clinics can reduce mortality and improve quality of life. However, it is important that the clinics are accompanied by action. There needs to be some mechanism to ensure that assessment by a nurse is followed by appropriate prescribing. Furthermore, the clinics need to be sustained.

\section{REFERENCES}

1 Department of Health. National Service Framework for Coronary Heart Disease. London: Department of Health, 2000.

2 Scottish Intercollegiate Guidelines Network. Secondary prevention of coronary heart disease following myocardial infarction. Guideline 41. Edinburgh: SIGN, 2000.

3 Cupples ME, McKnight A. Randomised controlled trial of health promotion in general practice for patients at high cardiovascular risk. BMJ 1994;309:993-6.

4 Cupples ME, McKnight A. Five year follow up of patients at high cardiovascular risk who took part in randomised controlled trial of health promotion. BMJ 1999;319:687-8.

5 Campbell NC, Thain J, Deans HG, et al. Secondary prevention clinics for coronary heart disease: randomised trial of effect on health. BMJ 1998;316:1434-7.

6 Murchie P, Campbell NC, Ritchie LD, et al. Secondary prevention clinics for coronary heart disease: four year follow up of a randomised trial in primary care. BMJ 2003:326:84-7.

7 Moher M, Yudkin P, Wright L, et al. Cluster randomised controlled trial to compare three methods of promoting secondary prevention of coronary heart disease in primary care. BMJ 2001;322:1338-42.

8 Allen JK, Blumenthal RS, Margolis S, et al. Nurse case management of hypercholesterolemia in patients with coronary heart disease: results of a randomized clinical trial. Am Heart J 2002;144:678-86.

\section{DISCUSSION}

Question: Regarding the lack of movement on smoking, I think that the changes that have occurred in the past five years-blocking of advertising, the television advertisements showing smokers dying, and also free nicotine replacement therapy-have led to a major change in attitude about stopping smoking. And I think you would find very different figures now. On another point, nurses are good at doing measurements, but quite often they are disempowered from making changes because of the attitude of the doctors-they know that they should have an increase in statins but somehow the doctors are not actually allowing it to happen. How did the practices that you looked at empower the nurses, and why is that other nurse clinics, maybe in Warwickshire, don't have empowered nurses?

Dr Campbell: I can't say what happened in Warwickshire, I think they would claim that they had better baselines scores so there was less room for improvement, but that meant that their mean cholesterol levels were somewhere in the $5 \mathrm{~s}$. In the American study, the mean cholesterol levels were 4.6 [mmol/l] in the control group but the nurses were able to follow protocol driven prescribing and they got the mean down to $4.1[\mathrm{mmol} / \mathrm{l}]$, so even starting from a low level it can be reduced given the opportunity for nurses to prescribe. Anecdotally, from talking to the practices that took part in our study, it was helpful if one GP in the practice was enthusiastic about the clinics and the nurse and the GP formed a sort of alliance, rather than trying to deal with all the personal list GPs independently. Not everybody is as enthusiastic about secondary prevention; other doctors prioritise other things, so I think it was helpful if there was some close link.

Question: In our practice we implemented a secondary prevention clinic about a year ago, and we have seen a dramatic improvement. This was without knowing the research. It just seemed to be a good idea. With the new General Medical Services contract, we are likely to see a huge 
growth in initiatives such as this. I am interested in your thoughts about what it is that makes certain secondary prevention clinics work, because one can envisage that with thousands of clinics popping up in practices across the country there will be ones that do work and ones that don't. From the evidence you have cited, and perhaps from publication bias which might only include ones that have worked, have you got feelings about what we should avoid and the pitfalls that could be avoided to make sure that the secondary prevention clinics are effective?

Dr Campbell: I think that so far the only comparative trial was Michael Moher's study in Warwickshire, where they ran nurse led secondary prevention clinics and compared them with recall to general practitioners and compared that to just audit and feedback to the practices. There is no doubt that the nurses were better than the general practitioners. So the more you can handle with nurses the better. But I do think that the other trials, and other studies looking at various initiatives to try to improve secondary prevention in different ways, have broken down at the point at which the GPs have to write a prescription. Whether that may have been worse in the past when the evidence was not quite so good and the guidelines were not available I don't know. I hope that things are better now. 